\title{
Article \\ Determinants of Quality of Life after Stroke in Southern Portugal: A Cross Sectional Community-Based Study
}

\author{
Eva Lourenço ${ }^{1,2,3, *}$, Mário Rui dos Mártires Sampaio ${ }^{3,4}$, Hipólito Nzwalo ${ }^{5,6}$ (D) Emília Isabel Costa ${ }^{3,7}$ (D) \\ and José Luis Sánchez Ramos ${ }^{8}$ (D) \\ 1 Doctoral School, Huelva University, 21001 Huelva, Spain \\ 2 Intensive Care Unit, Algarve University Hospital Center, 8000 Faro, Portugal \\ Nursing Department, Algarve University, 8000 Faro, Portugal; mariosampaio@hotmail.com (M.R.d.M.S.); \\ eicosta@ualg.pt (E.I.C.) \\ 4 Tavira Health Center, Algarve Health Administration, 8800 Tavira, Portugal \\ 5 Faculty of Medicine and Biomedical Sciences, Algarve University, 8000 Faro, Portugal; nzwalo@gmail.com \\ Stroke Unit, Algarve University Hospital Center, 8000 Faro, Portugal \\ Health Sciences Research Unit: Nursing, 3000 Coimbra, Portugal \\ 8 Nursing Department, Huelva University, 21001 Huelva, Spain; jsanchez@uhu.es \\ * Correspondence: ep111979@hotmail.com
}

Citation: Lourenço, E.; Sampaio, M.R.d.M.; Nzwalo, H.; Costa, E.I.; Ramos, J.L.S. Determinants of Quality of Life after Stroke in Southern Portugal: A Cross Sectional Community-Based Study. Brain Sci. 2021, 11, 1509. https://doi.org/ 10.3390/brainsci11111509

Academic Editor: Giovanni Morone

Received: 2 October 2021

Accepted: 11 November 2021

Published: 14 November 2021

Publisher's Note: MDPI stays neutral with regard to jurisdictional claims in published maps and institutional affiliations.

Copyright: (c) 2021 by the authors. Licensee MDPI, Basel, Switzerland. This article is an open access article distributed under the terms and conditions of the Creative Commons Attribution (CC BY) license (https:/ / creativecommons.org/licenses/by/ $4.0 /)$.

\begin{abstract}
Introduction: the perception of Quality of Life (QoL) has been used to evaluate the treatment and evolution of several pathologies. QoL evaluation allows a better understanding of the patient and his adaptation to the disease. An observational, community-based and descriptive correlational study was carried out to analyze stroke survivors' perception of QoL. Methods: consecutive caseseries of stroke survivors ( $\geq 3$ months) followed in a single public primary health center ("Tavira Primary Health Centre") from Algarve, southern Portugal. The Portuguese version of the World Health Organization Quality of life instrument was administered in 102 stroke survivors. Results: Perception of QoL was associated $(p<0.05)$ with specific sociodemographic (age, sex, marital status, academic training), economic (monthly family income) and clinical factors (number of vascular risk factors, type of stroke, evolution, chronic mRankin score). On multivariate analysis, chronic mRankin score on physical $\left(R^{2}=0.406 ; \mathrm{F}=8.757 ; p<0.001\right)$, psychological $\left(\mathrm{R}^{2}=0.286 ; \mathrm{F}=5.536\right.$; $p<0.001)$ and general domain $\left(R^{2}=0.357 ; F=7.287 ; p<0.001\right)$; and family income $\left(R^{2}=0.160\right.$; $\mathrm{F}=3.156 ; p<0.005)$ on environmental domain, emerged as predictors of QoL. Conclusion: Different socio-demographic, economic and health factors are associated with post-stroke QoL. Description of QoL contributes to the overall evaluation of the impact of stroke on health and should be a priority for health professionals.
\end{abstract}

Keywords: Quality of Life; health related quality of life; acute myocardial infarction; stroke

\section{Introduction}

Despite the decline of incidence and mortality rates [1], stroke remains a leading cause of morbidity worldwide [2]. Most studies addressing the health impact of stroke are based on short, long-term mortality and functional neurological outcome. However, even in patients without significant neurological disability, stroke can be associated with poor Quality of Life (QoL) [3-6]. QoL measurements are potentially more relevant and informative to patients than the evaluation of functional outcomes [7]. QoL evaluation may uncover insufficiently managed chronic health problems or facilitate a much broader description of stroke impact on survivors [8]. Worldwide, there are few studies addressing QoL among stroke survivors. These studies have identified factors such as functional status, depression, low socioeconomic status, or pain as the main determinants of QoL in stroke survivors [5,6,8-11]. Despite the extreme importance for patients and community, there are no community based published studies describing the QoL of stroke survivors in Portugal. 
Therefore, we sought to investigate which factors determine QoL of stroke survivors in a community representative population of Algarve, the southernmost part of Portugal.

\section{Materials and Methods}

\subsection{Setting and Sample}

A cross-sectional, descriptive study was carried out between February to September 2018 on consecutively presenting stroke survivors from a single public primary health care unit, the Tavira Health Centre in Tavira, Algarve. The centre serves a population of about 26,100 inhabitants [12]. Primary health care in Portugal is universally free and is the main place of regular patient follow-up for the majority of acute and chronic health conditions. The institutional electronic database was used to identify the patients meeting the following inclusion criteria: $>18$ years at the time of diagnosis; stroke diagnosed at least 3 months apart; followed at the Tavira Health Center. Patients were excluded in the presence of neurological deficits preventing effective communication and incomplete medical history. We used the World Health Organization (WHO) definition of stroke, "clinical syndrome of sudden onset of rapidly developing symptoms and signs of focal or global cerebral deficit with symptom lasting more than $24 \mathrm{~h}$ or leading to death with no apparent cause other than vascular origin" [13] confirmed by imaging.

The following variables were extracted from the electronic database: age, gender, marital status, formal education, employment status, income, existence of a caregiver, cardiovascular risk factors (hypertension, smoking, type 2 diabetes, sedentary lifestyle, obstructive apnea syndrome (OSAS), type 1 diabetes, alcoholism, atrial fibrillation, ischemic heart disease, dyslipidemia, obesity, hyperuricemia), functional neurological status (modified Rankin Scale or mRankin) [14]; stroke classification ("Oxfordshire Community Stroke Project" [15]-OCSP), previous medication and clinical evolution/sequelae and admission through "Vía Verde" or stroke code (a set of procedures aiming to rapidly provide acute reperfusion treatments in patients with stroke).

\subsection{Health-Related Quality of Life}

Health related Quality of life (HRQoL) is a multidimensional medical study questionnaire developed by WHO. The WHOQoL-BREF (abbreviated) version 2.0 has 26 questions and was translated and validated to Portuguese language [16,17]. These 26 questions access the individual's perceptions of their health and well-being over the previous two weeks. Responses to questions are on a 1-5 Likert scale where 1 represents "disagree" or "not at all" and 5 represents "completely agree" or "extremely". Every six questions cover one of four domains: Physical, Psychological, Social, Environment. Two questions access a General domain. The WHOQoL-BREF questionnaire takes about 15 minutes to complete and was administered in a face-to-face interview.

\subsection{Statistical Analysis}

For descriptive and inferential statistics Statistical Package for the Social Sciences (SPSS), version 21.0, was used. Continuous variables were expressed as mean and standard deviation, and categorical variables were expressed as percentages. Linear association between quantitative variables was evaluated by Pearson correlation coefficient. Spearman correlation coefficient was used in case variables did not present normality and for ordinal variables. T test was applied to variables with normal distribution, in order to determine whether the results were statistically different. Non-parametric tests, such as the MannWhitney test (2 independent samples) and the Kruskal-Wallis test (>2 independent samples) were applied when one of the variables had less than 30 individuals or did not present normal distribution. For each domain of the WHOQoL-BREF logistic, regression analysis was used to identify predictors associated with the QoL of stroke survivors. The statistical significance of all tests was set as $p<0.05$ by 2 -tailed tests. The Algarve Regional Research Ethics Committee approved the study in accordance with the Helsinki Declaration of 1983 (CES 34/2018). All subjects provided informed consent. 


\section{Results}

Of the 120 persons who met the inclusion criteria and could be located, $102(85.8 \%)$ agreed to participate and completed the questionnaire. Tables 1 and 2 resume, respectively, the sociodemographic and clinical characteristics of the patients included in the study. Table 1 shows that the majority $(65 / 63.7 \%)$ were men and the mean age at the diagnosis of stroke was 67.7 years old (SD: 12.3). The mean time between the stroke event and the questionnaire was 29.52 months (SD: 32). Most of the patients were married (65/63.7\%), had four years of schooling (55/53.9\%), were retired (69/67.6\%) and had an income lower than 580 euros $(47 / 46.1 \%)$.

Table 1. Sociodemographic characteristics of the stroke survivors $(n=102)$.

\begin{tabular}{|c|c|c|}
\hline Sociodemographic Characteristics & Average & SD \\
\hline \multicolumn{3}{|l|}{ Gender } \\
\hline \multicolumn{3}{|l|}{ Age } \\
\hline Current age & 70.23 & 12.6 \\
\hline Age at stroke onset & 67.75 & 12.3 \\
\hline \multirow[t]{2}{*}{ Difference (months) } & 29.52 & 32 \\
\hline & $\mathrm{N}$ & $\%$ \\
\hline \multicolumn{3}{|l|}{ Gender } \\
\hline Male & 65 & 63.7 \\
\hline Female & 37 & 36.3 \\
\hline \multicolumn{3}{|l|}{ Marital status } \\
\hline Single & 6 & 5.9 \\
\hline Married/Unmarried couple & 65 & 63.7 \\
\hline Widowed & 21 & 20.6 \\
\hline Divorced/Separate & 10 & 9.8 \\
\hline \multicolumn{3}{|l|}{ Formal education } \\
\hline Can't read or write & 8 & 7.8 \\
\hline Never went to school, but knows how to read and write & 12 & 11.8 \\
\hline 4 years & 55 & 53.9 \\
\hline 6 years & 1 & 1 \\
\hline 9 years & 12 & 11.8 \\
\hline 12 years & 8 & 7.8 \\
\hline Bachelor/Degree & 6 & 5.9 \\
\hline \multicolumn{3}{|l|}{ Employment status } \\
\hline Employed & 18 & 17.6 \\
\hline Unemployed & 3 & 2.9 \\
\hline Sick leave & 12 & 11.8 \\
\hline Retired & 69 & 67.6 \\
\hline \multicolumn{3}{|l|}{ Family income } \\
\hline Less minimal wage & 47 & 46.1 \\
\hline Between 1 and 2 minimal wages & 42 & 41.2 \\
\hline 3 or more minimal wages & 13 & 12.7 \\
\hline
\end{tabular}


Table 1. Cont.

\begin{tabular}{cccc}
\hline \multicolumn{2}{c}{ Sociodemographic Characteristics } & Average & SD \\
\hline \multicolumn{3}{r}{} & Existence of caregiver? \\
\hline Yes & 51 & $(50)$ \\
\hline No & 51 & $(50)$ \\
\hline
\end{tabular}

Table 2. Clinical characteristics of the stroke survivors $(n=102)$.

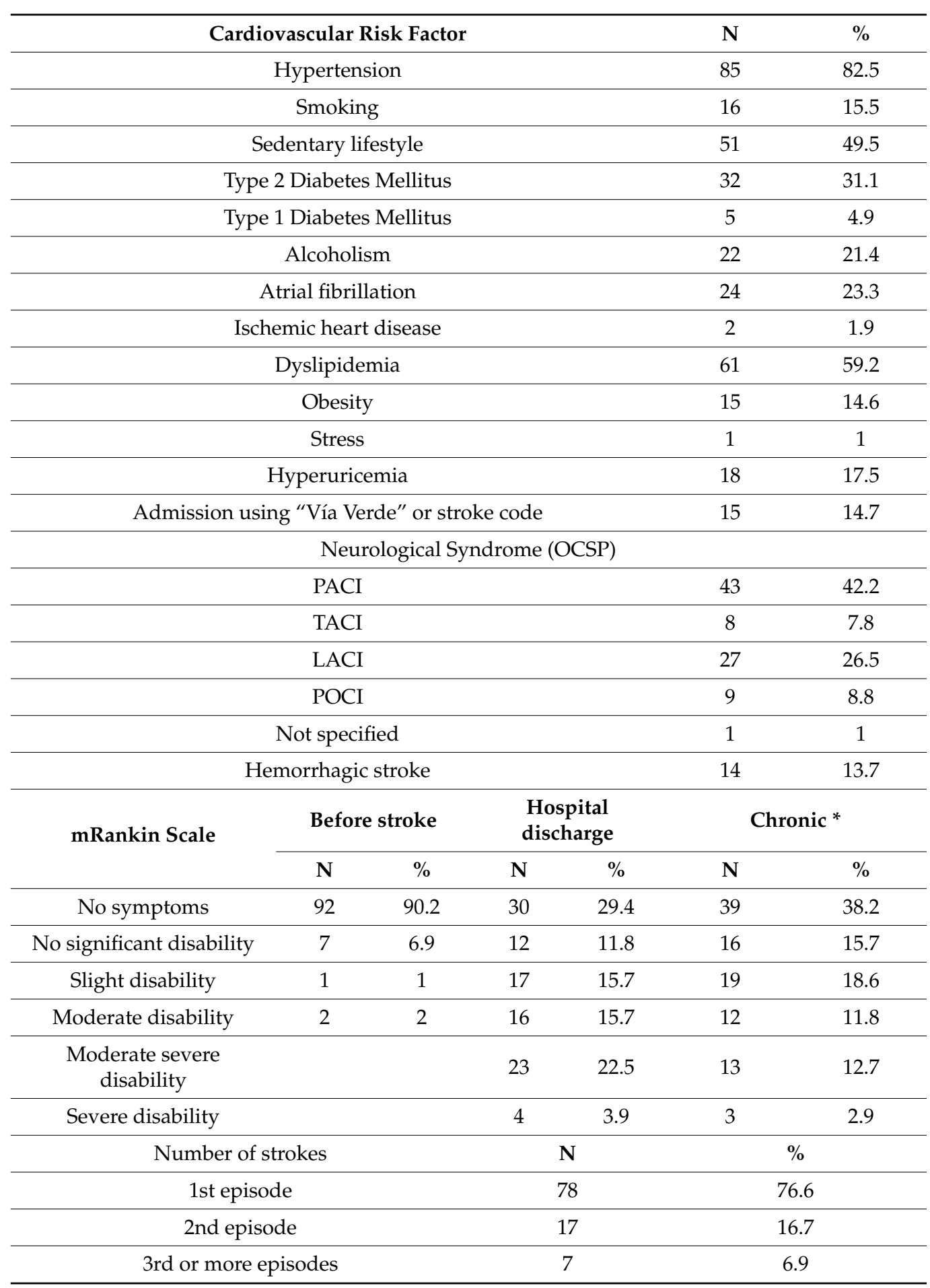


Table 2. Cont.

\begin{tabular}{ccc}
\hline \multicolumn{2}{c}{ Cardiovascular Risk Factor } & N \\
& Treatment & \% \\
\hline Fibrinolysis & 11 & 10.8 \\
\hline Conservative & 82 & 80.4 \\
\hline Surgery & 2 & 2 \\
\hline Stent angioplasty & 4 & 3.9 \\
\hline Thrombectomy & 3 & 2.9 \\
\hline & Clinical evolution & \\
\hline Positive without sequelae & 29 & 28.4 \\
\hline Negative with sequelae & 73 & 71.6 \\
\hline
\end{tabular}

OCSP-Oxfordshire Community Stroke Project; TACI—total anterior circulation infarcts; PACI—partial anterior circulation infarcts; LACI-lacunar circulation infarcts; POCI—posterior circulation infarcts; ${ }^{*}$ mRankin Scale at the time of the questionnaire application.

Ischemic stroke was the most common type $(87 / 86.4 \%)$. The most prevalent risk factors at the time of the vascular event were hypertension $(85 / 82.5 \%)$, dyslipidemia $(61 / 59.2 \%)$ and sedentary lifestyle (51/49.5\%). The proportion of stroke survivors with any functional neurological dependency was $10(9.9 \%), 72(69.5 \%)$ and $63(61.6 \%)$, before stroke, immediately after stroke and at the time of the questionnaire (from December 2018 to June $2019)$, respectively (Table 2). The majority of patients had a single stroke (78/76.6\%); 82 patients $(80.4 \%)$ did not receive any acute reperfusion treatment; only 29 patients had a positive clinical evolution without neurological sequelae.

Tables 3 and 4 resume the analysis of the association between specific domains of the HRQoL with different sociodemographic and clinical variables, respectively.

Table 3. Association between HRQoL domains and sociodemographic variables $(n=102)$.

\begin{tabular}{|c|c|c|c|c|c|}
\hline Variable & General & Physical & Psychological & Social & Environmental \\
\hline Current age & & $\begin{array}{c}\mathrm{R}=-0.262 \\
p=0.0081\end{array}$ & & $\begin{aligned} \mathrm{R} & =-0.247 \\
p & =0.0121\end{aligned}$ & \\
\hline Civil Status & $\begin{array}{c}\mathrm{H}=12.891 \\
\text { d.f. }=3 \\
p=0.0052\end{array}$ & $\begin{array}{c}\mathrm{H}=13.141 \\
\text { d.f. }=3 \\
p=0.0042\end{array}$ & $\begin{array}{c}\mathrm{H}=17.099 \\
\text { d.f. }=3 \\
p=0.0012\end{array}$ & $\begin{array}{c}\mathrm{H}=14.505 \\
\text { d.f. }=3 \\
p=0.0022\end{array}$ & \\
\hline $\begin{array}{c}\text { Formal } \\
\text { education }\end{array}$ & $\begin{array}{c}\text { Rho }=0.261 \\
p=0.0083\end{array}$ & $\begin{array}{c}\text { Rho }=0.368 \\
p=0.0013\end{array}$ & $\begin{array}{c}\text { Rho }=0.337 \\
p=0.0013\end{array}$ & $\begin{array}{c}\text { Rho }=0.354 \\
p=0.0013\end{array}$ & $\begin{array}{c}\text { Rho }=0.272 \\
p=0.0013\end{array}$ \\
\hline $\begin{array}{l}\text { Family } \\
\text { income }\end{array}$ & $\begin{array}{c}\text { Rho }=0.272 \\
p=0.0063 \\
\mathrm{t}=-2.147\end{array}$ & $\begin{array}{c}\text { Rho }=0.205 \\
p=0.0383 \\
\mathrm{t}=-3.340\end{array}$ & $\begin{array}{c}\text { Rho }=0.261 \\
p=0.0083 \\
\mathrm{t}=-2.652\end{array}$ & $\begin{array}{c}\text { Rho }=0.396 \\
p=0.0013 \\
\mathrm{t}=-3.823\end{array}$ & $\begin{array}{c}\text { Rho }=0.272 \\
p=0.0063\end{array}$ \\
\hline Retired & $\begin{array}{l}\text { d.f. }=101 \\
p=0.0344\end{array}$ & $\begin{array}{l}\text { d.f. }=101 \\
p=0.0014\end{array}$ & $\begin{array}{l}\text { d.f. }=101 \\
p=0.0094\end{array}$ & $\begin{array}{l}\text { d.f. }=101 \\
p=0.0014\end{array}$ & \\
\hline $\begin{array}{l}\text { Existence of a } \\
\text { caregiver }\end{array}$ & $\begin{array}{l}\mathrm{t}=-5.816 \\
\text { d.f. }=101 \\
p=0.0014\end{array}$ & $\begin{array}{l}\mathrm{t}=-6.890 \\
\text { d.f. }=101 \\
p=0.0014\end{array}$ & $\begin{array}{l}\mathrm{t}=-5.176 \\
\text { d.f. }=101 \\
p=0.0014\end{array}$ & $\begin{array}{l}\mathrm{t}=-3.192 \\
\text { d.f. }=101 \\
p=0.0024\end{array}$ & \\
\hline
\end{tabular}

R: Pearson correlation; H: Kruskal-Wallis test; t-Student test; Rho: Spearmann correlation.

Higher age at the time of stroke onset was negatively correlated with the physical $(p<0.01)$ and social $(p<0.05)$ dimensions of the HRQoL. Divorced survivors had higher average scores on physical, psychological, social, and general dimensions than married $(p<0.05)$ or widowed survivors $(p<0.01)$. Survivors with more years of school $(p<0.01)$ and higher family income $(p<0.05)$ had higher perception in all dimensions of the HRQoL. On the contrary, retired survivors $(p<0.05)$ and those with current need of caregivers $(p<0.01)$ had worse perception in multidomain of the HRQoL (Table 3$)$. 
Table 4. Association between HRQoL domains of the and clinical variables $(n=102)$.

\begin{tabular}{cccccc}
\hline Variable & General & Physical & Psychological & Social & Environmental \\
\hline $\begin{array}{c}\mathrm{N}^{\mathrm{o}} \text { vascular } \\
\text { risk factors }\end{array}$ & & & & $\mathrm{R}=-0.209$ & \\
$p=0.0341$ & \\
\hline No & $\mathrm{U}=476.5$ & $\mathrm{U}=426.5$ & $\mathrm{U}=290.5$ & $\mathrm{U}=439.5$ & \\
medication & $p=0.0062$ & $p=0.0022$ & $p<0.0012$ & $p=0.0022$ & \\
\hline Without & $\mathrm{U}=416.5$ & & $\mathrm{U}=504.0$ & \\
sequelae & $p=0.0052$ & & & $p=0.0402$ & \\
\hline Discharge & $\mathrm{Rho}=-0.487$ & $\mathrm{Rho}=-0.458$ & $\mathrm{Rho}=-0.402$ & $\mathrm{Rho}=-0.285$ & \\
mRankin & $p=0.0013$ & $p=0.0013$ & $p=0.0013$ & $p=0.0033$ & \\
\hline Chronic & $\mathrm{Rho}=-0.622$ & $\mathrm{Rho}=-0.629$ & $\mathrm{Rho}=-0.550$ & $\mathrm{Rho}=-0.314$ & \\
mRankin & $p=0.0013$ & $p=0.0013$ & $p=0.0013$ & $p=0.0013$ & \\
\hline Haemorrhagic & $\mathrm{U}=259.5$ & $\mathrm{U}=324.5$ & $\mathrm{U}=303.5$ & & \\
stroke & $p=0.0012$ & $p=0.0042$ & $p=0.0022$ & & $\mathrm{t}=2.679$ \\
\hline Clinical & $\mathrm{t}=6.133$ & $\mathrm{t}=5.571$ & $\mathrm{t}=5.472$ & $\mathrm{t}=4.686$ & $\mathrm{~d} . \mathrm{f}=101$ \\
evolution & $\mathrm{d} . \mathrm{f}=101$ & $\mathrm{~d} . \mathrm{f}=101$ & $\mathrm{~d} . \mathrm{f}=101$ & $\mathrm{~d} . \mathrm{f} .=101$ & \\
& $p=0.0014$ & $p=0.0014$ & $p=0.0014$ & $p=0.0014$ & $p=0.0094$ \\
\hline
\end{tabular}

R: Pearson correlation; U: Mann-Whitney test; t-Student test; Rho: Spearmann correlation.

Survivors who were taking medication or with comorbidities had worse perception of HRQoL in the physical, psychological, social, and general domains $(p<0.01)$ (Table 4$)$. In comparison to ischemic stroke survivors, patients who suffered a hemorrhagic stroke had worse perception in almost all dimensions of the HRQoL $(p<0.01)$.

On multivariate analysis (Tables 5-8) chronic mRS was the only predictor found for the physical domain $\left(R^{2}=0.406 ; F=8.757 ; p<0.001\right)$, the psychological domain $\left(R^{2}=0.286\right.$; $\mathrm{F}=5.536 ; p<0.001)$ and the general domain $\left(\mathrm{R}^{2}=0.357 ; \mathrm{F}=7.287 ; p<0.001\right)$. Chronic mRS explained $40.6 \%, 28.6 \%$ and $35.7 \%$ of the variance, respectively. For the environmental domain, monthly family income emerged as a predictor, explaining $6 \%$ of the variance $\left(\mathrm{R}^{2}=0.160 ; \mathrm{F}=3.156 ; p<0.005\right)$.

Table 5. Multivariate analysis for Physical domain.

\begin{tabular}{|c|c|c|c|c|c|c|c|}
\hline \multirow[t]{2}{*}{ Physical Domain } & \multicolumn{2}{|c|}{$\begin{array}{l}\text { Unstandardized } \\
\text { Coefficients }\end{array}$} & \multirow{2}{*}{$\begin{array}{c}\begin{array}{c}\text { Standardized } \\
\text { Coefficients }\end{array} \\
\text { Beta }\end{array}$} & \multirow[t]{2}{*}{$\mathbf{t}$} & \multirow[t]{2}{*}{ Sig. } & \multicolumn{2}{|c|}{ 95\% Conf. Int. } \\
\hline & B & Std. Error & & & & & \\
\hline (Constant) & 70.566 & 11.164 & & 6.321 & 0.000 & 48.396 & 92.736 \\
\hline Current age & 4.954 & 3.636 & 3.346 & 1.363 & 0.176 & -2.266 & 12.174 \\
\hline Disease age & -5.054 & 3.640 & -3.330 & -1.388 & 0.168 & -12.283 & 2.175 \\
\hline Difference (months) & -0.445 & 0.316 & -0.761 & -1.406 & 0.163 & -1.073 & 0.184 \\
\hline Sex & -2.341 & 3.115 & -0.061 & -.751 & 0.454 & -8.527 & 3.846 \\
\hline Family income & 3.144 & 2.225 & 0.117 & 1.413 & 0.161 & -1.274 & 7.562 \\
\hline $\begin{array}{c}\text { Number of } \\
\text { Cardiovascular Risk } \\
\text { Factors }\end{array}$ & -1.175 & 1.084 & -0.088 & -1.085 & 0.281 & -3.327 & 0.977 \\
\hline Previous mRankin & 2.216 & 3.003 & 0.061 & 0.738 & 0.463 & -3.748 & 8.180 \\
\hline Discharge mRankin & 0.802 & 1.541 & 0.071 & 0.520 & 0.604 & -2.259 & 3.863 \\
\hline Chronic mRankin & -7.761 & 1.674 & -0.645 & -4.637 & 0.000 & -11.084 & -4.438 \\
\hline
\end{tabular}


Table 6. Multivariate analysis for Psychological domain.

\begin{tabular}{|c|c|c|c|c|c|c|c|}
\hline \multirow{2}{*}{$\begin{array}{c}\text { Psychological } \\
\text { Domain }\end{array}$} & \multicolumn{2}{|c|}{$\begin{array}{c}\text { Unstandardized } \\
\text { Coefficients }\end{array}$} & \multirow{2}{*}{$\begin{array}{c}\text { Standardized } \\
\text { Coefficients }\end{array}$} & \multirow[t]{2}{*}{$\mathbf{t}$} & \multirow[t]{2}{*}{ Sig. } & \multirow{2}{*}{\multicolumn{2}{|c|}{ 95\% Conf. Int. }} \\
\hline & B & Std. Error & & & & & \\
\hline (Constant) & 72.729 & 12.245 & & 5.940 & 0.000 & 48.414 & 97.045 \\
\hline Current age & 3.890 & 3.988 & $2-627$ & 0.975 & 0.332 & -4.029 & 11.809 \\
\hline Disease age & -3.836 & 3.993 & -2.528 & -0.961 & 0.339 & -11.765 & 4.093 \\
\hline Difference (months) & -0.368 & 0.347 & -0.630 & -1.062 & 0.291 & -1.057 & 0.320 \\
\hline Sex & -5.849 & 3.417 & -0.152 & -1.712 & 0.090 & -12.634 & 0.936 \\
\hline Family income & 0.601 & 2.440 & 0.022 & 0.246 & 0.806 & -4.244 & 5.447 \\
\hline $\begin{array}{c}\text { Number of } \\
\text { Cardiovascular Risk } \\
\text { Factors }\end{array}$ & -0.606 & 1.189 & -0.045 & -0.510 & 0.611 & -2.966 & 1.754 \\
\hline Previous mRankin & -1.316 & 3.294 & -0.036 & -0.399 & 0.690 & -7.857 & 5.225 \\
\hline Discharge mRankin & 0.866 & 1.691 & 0.077 & 0.512 & 0.610 & -2.491 & 4.223 \\
\hline Chronic mRankin & -7.175 & 1.836 & -0.597 & -3.909 & 0.000 & -10.820 & -3.530 \\
\hline
\end{tabular}

Table 7. Multivariate analysis for General domain.

\begin{tabular}{|c|c|c|c|c|c|c|c|}
\hline \multirow[t]{2}{*}{ General Domain } & \multicolumn{2}{|c|}{$\begin{array}{l}\text { Unstandardized } \\
\text { Coefficients }\end{array}$} & \multirow{2}{*}{$\begin{array}{c}\begin{array}{c}\text { Standardized } \\
\text { Coefficients }\end{array} \\
\text { Beta }\end{array}$} & \multirow[t]{2}{*}{$\mathbf{t}$} & \multirow[t]{2}{*}{ Sig. } & \multirow{2}{*}{\multicolumn{2}{|c|}{ 95\% Conf. Int. }} \\
\hline & B & Std. Error & & & & & \\
\hline (Constant) & 65.020 & 14.949 & & $4-350$ & 0.000 & 35.334 & 94.705 \\
\hline Current age & 2.550 & 4.868 & 1.339 & 0.524 & 0.602 & -7.118 & 12.217 \\
\hline Disease age & -2.445 & 4.874 & -1.253 & -0.502 & 0.617 & -12.125 & 7.234 \\
\hline Difference (months) & -0.171 & 0.423 & -0.227 & -0.404 & 0.687 & -1.012 & 0.670 \\
\hline Sex & -3.788 & 4.172 & -0.076 & -0.908 & 0.366 & -12.072 & 4.496 \\
\hline Family income & -2.122 & 2.979 & -0.061 & -0.712 & 0.478 & -8.038 & 3.794 \\
\hline $\begin{array}{c}\text { Number of } \\
\text { Cardiovascular Risk } \\
\text { Factors }\end{array}$ & -0.741 & 1.451 & -0.043 & -0.511 & 0.611 & -3.622 & 2.141 \\
\hline Previous mRankin & 1.309 & 4.021 & 0.028 & 0.325 & 0.746 & -6.677 & 9.294 \\
\hline Discharge mRankin & 0.935 & 2.064 & 0.065 & 0.453 & 0.652 & -3.163 & 5.034 \\
\hline Chronic mRankin & -11.108 & 2.241 & -0.718 & -4.957 & 0.000 & -15.558 & -6.658 \\
\hline
\end{tabular}

Table 8. Multivariate analysis for Environmental domain.

\begin{tabular}{|c|c|c|c|c|c|c|c|}
\hline \multirow{2}{*}{$\begin{array}{c}\text { Environmental } \\
\text { Domain }\end{array}$} & \multicolumn{2}{|c|}{$\begin{array}{l}\text { Unstandardized } \\
\text { Coefficients }\end{array}$} & \multirow{2}{*}{$\begin{array}{c}\begin{array}{c}\text { Standardized } \\
\text { Coefficients }\end{array} \\
\text { Beta }\end{array}$} & \multirow[t]{2}{*}{$\mathbf{t}$} & \multirow[t]{2}{*}{ Sig. } & \multicolumn{2}{|c|}{ 95\% Conf. Int. } \\
\hline & B & Std. Error & & & & & \\
\hline (Constant) & 50.166 & 9.844 & & 5.096 & 0.000 & 30.618 & 69.713 \\
\hline Current age & -0.305 & 3.206 & -0.278 & -0.095 & 0.924 & -6.671 & 6.061 \\
\hline Disease age & 0.246 & 3.210 & 0.219 & 0.077 & 0.939 & -6.128 & 6.620 \\
\hline Difference (months) & 0.128 & 0.279 & 0.296 & 0.459 & 0.647 & -0.426 & 0.682 \\
\hline Sex & 1.435 & 2.747 & 0.050 & 0.522 & 0.603 & -4.020 & 6.890 \\
\hline Family income & 7.393 & 1.962 & 0.371 & 3.769 & 0.000 & 3.497 & 11.288 \\
\hline $\begin{array}{c}\text { Number of } \\
\text { Cardiovascular Risk } \\
\text { Factors }\end{array}$ & 0.802 & 0.955 & 0.081 & 0.839 & 0.403 & -1.096 & 2.699 \\
\hline Previous mRankin & -2.466 & 2.648 & -0.092 & -0.931 & 0.354 & -7.725 & 2.792 \\
\hline Discharge mRankin & -1.002 & 1.359 & -0.121 & -0.737 & 0.463 & -3.701 & 1.697 \\
\hline Chronic mRankin & -0.420 & 1.476 & -0.047 & -0.285 & 0.777 & -3.350 & 2.510 \\
\hline
\end{tabular}




\section{Discussion}

This is the first community-based study describing the QoL of stroke survivors in our country. The study demonstrated that in stroke survivors, several sociodemographic factors (being older, widow, less educated), economic factors (lower monthly family income) and clinical factors (hemorrhagic stroke type, comorbidities, high chronic mRankin score) are associated with reduced perception of QoL in different dimensions. These findings are similar to those reported in previous studies [5,6,8-11]. A large proportion of stroke survivors have poor perception of their QoL and probably face unmet long-term needs [6]. Sociodemographic, economic and health factors have been shown to influence the QoL of stroke survivors [18-20]. The relatively young age at the time of stroke, as well at the time of QoL evaluation, further emphasizes the potential for long-term impact and great repercussions to the survivors and consequently for the society $[19,20]$. QoL is very complex and dependent on several factors. For instance, in our study we have demonstrated that widowed survivors have poor QoL. However, widowed patients are generally older, at greater risk of functional decline and poor social support. In addition, the grieving process, per se, negatively impacts various aspects of physical and mental health that can lead to a decrease in the perception of QoL [19-21].

Indeed, among older patients and in patients with lower education, reduced HRQoL has been shown to be multifactorial $[6,11]$. Compliance with post-stroke management including rehabilitation, control of vascular risk factors; access to supporting networks within or outside the family helps improve the perception of QoL [8]. Low education and income influence the ability to control cardiovascular risk factors and the treatment of stroke, due to the difficulty in implementing preventive measures and problems in accessing information, treatment, and rehabilitation services [11]. Patients may encounter financial barriers to accessing high cost treatments, resulting in a cycle of health degradation and worse perception of QoL [6]. Additionally, the effort to put in place specific prevention strategies, including restrictive diets, adoption of healthy behaviors, and chronic use of medications - which are sometimes very expensive — can further cause low perception of QoL [6,8].

In our study, only chronic mRankin and income emerged as a predictor of poorer QoL. The mRankin scale is used to evaluate the functional neurological outcome after stroke and is one of the most widely used scales [11,22]. Therefore, it is expected that a higher mRankin score or higher dependency would be associated with a lower perception of QoL. Others have also demonstrated that patients with worse functional outcomes or more severe strokes have poor perception on some specific domains of HRQoL such as physical, psychological, and general health. These domains are highly associated with autonomy or dependence on their caregivers [8,22]. Improvement of post-stroke QoL demands an integrated view of each patient. Management of specific social or health problems, for instance, spasticity, can have a large impact in multiple domains of QoL [23].

The percentage of ischemic stroke versus haemorrhagic stroke is similar to that described in the medical literature, where it is reported that around $85-90 \%$ of all strokes are ischemic and the remaining are haemorrhagic strokes [24]. Despite that, haemorrhagic stroke is often more deadly than ischemic stroke. The justification may be related to the pathophysiology of the stroke itself, which may lead to a lower response of deficits to rehabilitation, more sequelae, greater dependence, and dysfunction, and consequently a worse perception of QoL [8,9,24].

There are several limitations to be considered. Depression, a major contributor for HQoL $[3,16,18]$ was not specifically evaluated. The inclusion of mental health in the HRQoL partially attenuates this limitation. There is no consensus on when to evaluate the QoL of post-stroke patients. We evaluated patients with different post-stroke follow-up durations, which may have reduced the possibility of identifying meaningful differences. Nevertheless, in some studies, on the long-term follow-up no significant changes occurred in perception of QoL in stroke survivors [9,21]. Finally, the number of participants was small, preventing a more detailed and robust statistical analysis. 


\section{Conclusions}

Stroke long term health impact constitutes an important problem for survivors, relatives, caregivers, and society. Measuring HRQoL in post-stroke patients represents an important contribution to the better understanding of the overall health status of stroke survivors and should be prioritized for health professionals [5].

Our study showed that the patient's subjective wellbeing is influenced by social, economic and health factors. Further studies, with larger samples, are needed in order to analyse the relationship between QoL and different clinical and socio-economic factors.

Author Contributions: Conceptualization, methodology and analysis-E.L., M.R.d.M.S., H.N., E.I.C. and J.L.S.R.; writing—original draft preparation-E.L., M.R.d.M.S.; writing-review-E.L., H.N., E.I.C., J.L.S.R. All authors have read and agreed to the published version of the manuscript.

Funding: This research received no external funding.

Institutional Review Board Statement: The study was conducted according to the guidelines of the Declaration of Helsinki, and approved by the Ethics Committee of Algarve Health Administration (CES 34/2018).

Informed Consent Statement: Informed consent was obtained from all subjects involved in the study.

Data Availability Statement: Authors agree to make data and materials supporting the results or analyses presented in their paper available upon reasonable request.

Conflicts of Interest: The authors declare no conflict of interest.

\section{References}

1. Feigin, V.L.; Norrving, B.; Mensah, G.A. Global Burden of Stroke. Circ. Res. 2017, 120, 439-448. [CrossRef] [PubMed]

2. Vos, T.; Abajobir, A.A.; Abate, K.H.; Abbafati, C.; Abbas, K.M.; Abd-Allah, F.; Abdulkader, R.S.; Abdulle, A.M.; Abebo, T.A.; Abera, S.F.; et al. Global, regional, and national incidence, prevalence, and years lived with disability for 328 diseases and injuries for 195 countries, 1990-2016: A systematic analysis for the Global Burden of Disease Study 2016. Lancet 2017, 390, 1211-1259. [CrossRef]

3. Jaracz, K.; Jaracz, J.; Kozubski, W.; Rybakowski, J.K. Post-stroke quality of life and depression. Acta Neuropsychiatr. 2002, 14, 219-225. [CrossRef]

4. Lai, S.M.; Studenski, S.; Duncan, P.; Perera, S. Persisting consequences of stroke measured by the stroke impact scale. Stroke 2002, 33, 1840-1844. [CrossRef]

5. Bergstrom, A.L.; Eriksson, G.; Von Koch, L.; Tham, K. Combined life satisfaction of persons with stroke and their caregivers: Associations with caregiver burden and the impact of stroke. Heal. Qual. Life Outcomes 2011, 9, 1-10. [CrossRef]

6. Pedersen, S.G.; Friborg, O.; Heiberg, G.A.; Arntzen, C.; Stabel, H.H.; Thrane, G.; Nielsen, J.F.; Anke, A. Stroke-Specific Quality of Life one-year post- stroke in two Scandinavian country-regions with different organisation of rehabilitation services: A prospective study. Disabil. Rehabil. 2020, 1, 1-11. [CrossRef]

7. Guyatt, G.H.; Feeny, D.H.; Patrick, D.L. Measuring health-related quality of life. Ann. Intern. Med. 1993, 118, 622-629. [CrossRef] [PubMed]

8. Carod-Artal, J.; Egido, J.A.; González, J.L.; Varela de Seijas, E. Quality of life among stroke survivors evaluated 1 year after stroke: Experience of a stroke unit. Stroke 2000, 31, 2995-3000. [CrossRef] [PubMed]

9. Choi-Kwon, S.; Choi, J.M.; Kwon, S.U.; Kang, D.-W.; Kim, J.S. Factors that Affect the Quality of Life at 3 Years Post-Stroke. J. Clin. Neurol. 2006, 2, 34. [CrossRef]

10. Abubakar, S.A.; Isezuo, S.A. Health related quality of life of stroke survivors: Experience of a stroke unit. Int. J. Biomed. Sci. IJBS 2012, 8, 183-187. [PubMed]

11. Mahesh, P.K.B.; Gunathunga, M.W.; Jayasinghe, S.; Arnold, S.M.; Liyanage, S.N. Factors influencing pre-stroke and post-stroke quality of life among stroke survivors in a lower middle-income country. Neurol. Sci. 2017, 39, 287-295. [CrossRef]

12. INE. Censos 2011 Resultados Definitivos-Região Algarve; Instituto Nacional de Estatística: Lisboa, Portugal, 2012; p. 96. ISBN 978-989-25-0183-3. ISSN 0872-6493.

13. WHO MONICA Project Investigators. The World Health Organization MONICA Project (Monitoring trends and determinants in cardiovascular disease). J. Clin. Epidemiol. 1988, 41, 105-114. [CrossRef]

14. Quinn, T.J.; Dawson, J.; Walters, M.R.; Lees, K.R. Reliability of the modified Rankin Scale: A systematic review. Stroke 2009, 40, 3393-3395. [CrossRef] [PubMed]

15. Smith, C.J.; Emsley, H.C.; Libetta, C.M.; Hughes, D.G.; Drennan, R.F.; Vail, A.; Tyrrell, P. The Oxfordshire Community Stroke Project classification in the early hours of ischemic stroke and relation to infarct site and size on cranial computed tomography. $J$. Stroke Cerebrovasc. Dis. 2001, 10, 205-209. [CrossRef] 
16. Lima, R.C.M.; Teixeira-Salmela, L.F.; Magalhaes, L.C.; Gomes-Neto, M. Psychometric properties of the Brazilian version of the Stroke Specifi c Quality of Life Scale: Application of the Rasch model. Braz. J. Phys. Ther. 2008, 12, 149-156.

17. Canavarro, M.C.; Pereira, M.; Moreira, H.; Paredes, T. Qualidade de Vida e Saúde: Aplicações do WHOQOL; Alicerces: Sao Paulo, Brazil, 2010; Volume 3, pp. 243-268.

18. Chen, T.; Zhang, B.; Deng, Y.; Fan, J.-C.; Zhang, L.; Song, F. Long-term unmet needs after stroke: Systematic review of evidence from survey studies. BMJ Open 2019, 9, e028137. [CrossRef]

19. Viitanen, M.; Fugl-Meyer, K.S.; Bernspång, B.; Fugl-Meyer, A.R. Life satisfaction in long-term survivors after stroke. Scand. J. Rehabil. Med. 1988, 20, 17-24.

20. King, R. Quality of life after stroke. Stroke 1996, 27, 1467-1472. [CrossRef]

21. Hackett, M.L.; Duncan, J.R.; Anderson, C.S.; Broad, J.B.; Bonita, R. Health-related quality of life among long term survivors of stroke: Results from the Auckland Stroke Study, 1991-1992. Stroke 2000, 31, 440-447. [CrossRef]

22. Drummond, A.E.R. Stroke: The Impact on the Family. Br. J. Occup. Ther. 1988, 51, 193-194. [CrossRef]

23. Turcu-Stiolica, A.; Subtirelu, M.S.; Bumbea, A.M. Can Incobotulinumtoxin-A Treatment Improve Quality of Life Better Than Conventional Therapy in Spastic Muscle Post-Stroke Patients? Results from a Pilot Study from a Single Center. Brain Sci. 2021, 11, 934. [CrossRef] [PubMed]

24. Unnithan, A.K.A.; Mehta, P. Hemorrhagic Stroke. In StatPearls; StatPearls Publishing: Treasure Island, FL, USA, 2021. [PubMed] 